
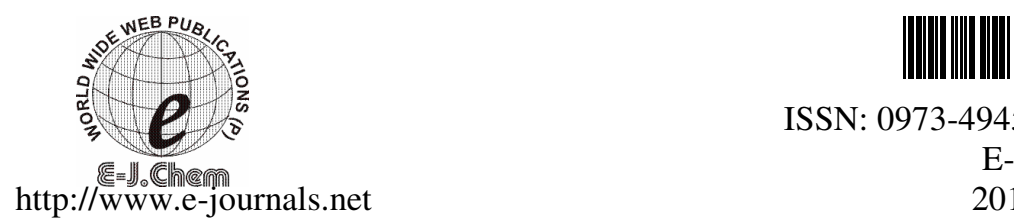

ISSN: 0973-4945; CODEN ECJHAO

E-Journal of Chemistry

2010, 7(S1), S223-S230

\title{
Studies on the Solute Solvent Interaction of Nimesulide in Aqueous Solutions of Hydrotropic Agents at Different Temperatures
}

\author{
CHANDRAVIR S. SOLANKI, SUSHREE TRIPATHY ${ }^{\S}$, \\ MINAKETAN TRIPATHY ${ }^{{ }^{*}}$ and UPENDRA N.DASH ${ }^{\#}$ \\ Indira Gandhi Institute of Pharmaceutical Sciences \\ Nayapalli, Bhubaneswar, India \\ ${ }^{\S}$ Faculty of Pharmacy, Universiti Teknologi MARA (UiTM) \\ Campus Puncak Alam, Selangor, 42300, Malaysia \\ "Department of Chemistry, ITER \\ SOA University, Bhubanesawr, 751030, India \\ minaketan@salam.uitm.edu.my
}

Received 31 March 2010; Accepted 24 May 2010

\begin{abstract}
The present study deals with experiments so as to highlight the solute (drug nimesulide) - solvent(water) interactions and related modifications in case of the presence of hydrotropic agents at different temperatures $\mathrm{T}(=298.15$ to 313.15$) \mathrm{K}$. Density and viscosity values of nimesulide have been determined in water in $(0.1,0.2,0.4,0.6,0.8,1$ and 2$) \mathrm{mol} \mathrm{dm}^{-3}$ aqueous solutions of hydrotropic agents (sodium benzoate, sodium salicylate, sodium bromide and nicotinamide) at temperatures $298.15,303.15,308.15$ and $313.15 \mathrm{~K}$ where as the solubility was studied at $308.15 \mathrm{~K}$. From the density values, the limiting partial molar volumes and expansibilities have been calculated. The experimental viscosity values have been analyzed in terms of jones-dole equation and on the basis of transition theory for relative viscosity.
\end{abstract}

Keywords: Nimesulide, Hydrotropic agents, Solubilities, Partial molar volumes, Viscosities.

\section{Introduction}

Solubility phenomenon is an area of particular importance. For the pharmaceutical researchers improving the water solubility of insoluble or slightly soluble compounds is a major concern. The aqueous solubility of drug is often a limiting factor in developing most desirable dosage form. Development of viable and suitable method of solubilisation is important, especially for new chemical entities. There are several techniques to enhance the 
solubility of poorly water soluble drugs, such as use of buffering agents and soluble salts, use of surface active agents (micellar solubilisation), hydrate and solvates, polymorphism, complexation, hydrotropic solubilisation and conventional trituration and grinding. Amongst these techniques, hydrotropic solubilisation is considered as one of the safest methods of solubilisation ${ }^{1,2}$. Aqueous solubilisation of insoluble drugs can be achieved by addition of hydrotropic agents. Nimesulide, is an acidic non steroidal anti- inflammatory agent, acts as an inhibitor of cyclooxygenase-II, hence inhibits the synthesis of destructive prostaglandins and spares the cytoprotective prostaglandins. Nimesulide is practically insoluble in water which precludes its use in parenteral formulations. Many work highlighted the effect of the solubility enhancers (hydrotropic agents) ${ }^{3,4}$ and hence improved solubility of the drug, but no detailed explanation is available relating to the improvement phenomenon. It is well known that volumetric and viscometric studies of solutes at definite and infinite dilution in a solvent system provide valuable information regarding the ion-ion and ion-solvent interactions. By examining the limiting apparent molar volume $\phi_{\mathrm{v}}{ }^{0}$, viscosity coefficient $\mathrm{B}_{\mathrm{J}}$ of ionic solutions as a function of size, nature, temperature and composition of the solvent, it is possible to examine the parameters on solute-solvent interaction with the hope of obtaining a better understanding of interactions in solutions. The present study deals with experiments so as to highlight the solute (drug nimesulide) - solvent (water) interactions and related modifications in case of the presence of hydrotropic agents at different temperatures 298.15 to $313.15 \mathrm{~K}$

\section{Experimental}

Sodium benzoate, sodium salicylate, sodium bromide and nicotinamide were of analytical reagents and kept over anhydrous $\mathrm{CaCl}_{2}$ in a vacuum desiccator until required. Nimesulide was a gift sample (procured from M/S Alkem Laboratory, Mumbai, India) and used as such. The solutions were prepared freshly by mass using a Metler balance with a precision of $\pm 0.01 \mathrm{mg}$ in doubly distilled deionized and degassed water and conversion of molality to molarity was done by standard expression ${ }^{5}$.

\section{Procedure}

\section{Solubility study}

Different concentrations $(0.1$ to $2.0 \mathrm{M})$ of each of the hydrotropic agents (sodium benzoate, sodium salicylate, sodium bromide and nicotinamide) were prepared separately in double distilled water using $100 \mathrm{~mL}$ conical flask and excess amount of drug, nimesulide was added to each flask containing the required molar solutions of the corresponding hydrotropic agents. All the conical flasks were put in a mechanical shaker maintained at the temperature of $308.15 \mathrm{~K}$ within an accuracy of $\pm 0.02 \mathrm{~K}$ and shaken for a maximum period of 6hours.After $6 \mathrm{~h}, 10 \mathrm{~mL}$ aliquot from each flask was withdrawn, filtered with a 0.5 micron filter paper and analyzed at $394 \mathrm{~nm}$ by UV double beam spectrophotometer for determining the aqueous solubility of nimesulide in different solutions of the four hydrotropic agents at temperature $308.15 \mathrm{~K}$.

\section{Measurement of density and Viscosity}

An anton paar digital densimeter (Model DMA 60/602) was used to measure the densities of the solutions. An efficient constant temperature bath with stability within $\pm 0.02 \mathrm{~K}$ was used to control the temperature of water around the densimeter cell. The densimeter was calibrated by using pure water and dry air. All the density measurements of the solutions were made relative to pure water. Densities of pure water at the experimental temperatures have been taken from the literature ${ }^{6}$. The densities have precision better than $\pm 10^{-3} \mathrm{~kg} \mathrm{~m}^{-3}$. 
Viscosities of the solutions of nimesulide in aqueous solutions of hydrotropic agents were measured with an Ostwald's viscometer at specific temperature with accuracy $\pm 0.02 \mathrm{~K}$. The viscometer was calibrated by measuring the viscosity of water in the temperature range between 298.15 and $313.15 \mathrm{~K}$ and the viscosity values agree very well with the literature values ${ }^{7}$. The viscosities have precision better than $\pm 10^{3} \mathrm{~kg} \mathrm{~m}^{-1} \mathrm{~s}^{-1}$.

\section{Results and Discussion}

\section{Solubilities}

The results of the solubility measurements of nimesulide in different molar concentrations of sodium benzoate, sodium salicylate, sodium bromide and nicotinamide along with that in double distilled water are shown in Figure 1, at different molar concentrations 0.1 to 2.0 mol $\mathrm{dm}^{-3}$ of the hydrotropic agents at $308.15 \mathrm{~K}$ only.

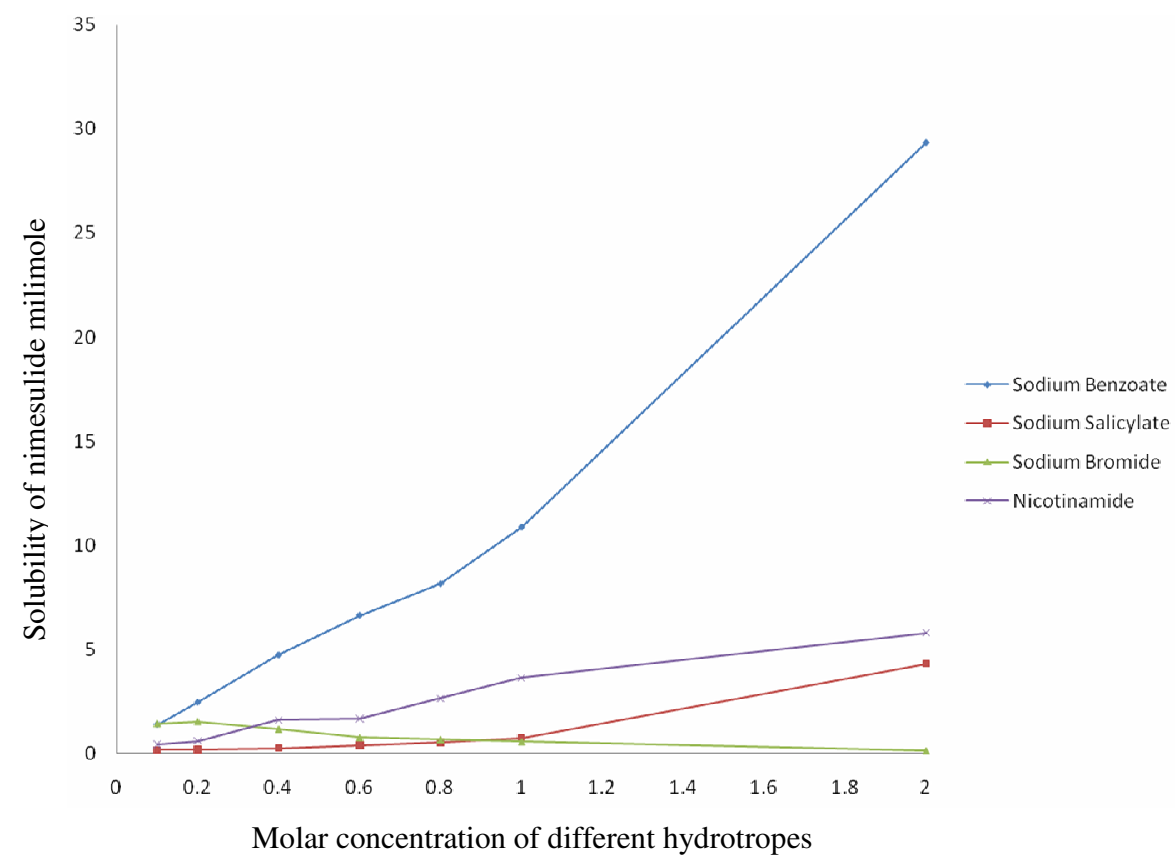

Figure 1. Solubility of nimesulide in different molar concentrations of sodium benzoate, sodium salicylate, sodium bromide and nicotinamide at $308.15 \mathrm{~K}$

It is seen that the solubility of nimesulide increases with time and approaches the limiting value at the time period of six hours .Further, its solubility increases with the increase in concentration of the hydrotropic agents (except sodium bromide). As observed, the poorly soluble drug, nimesulide is more soluble in all solutions of sodium benzoate, sodium bromide(excluding higher concentration ), nicotinamide and in $0.6,0.8,1.0$ and $2.0 \mathrm{~mol} \mathrm{dm}^{-3}$ sodium salicylate than in pure water. But, in $0.1 \mathrm{~mol} \mathrm{dm}^{-3}$ up to $0.4 \mathrm{~mol} \mathrm{dm}^{-3}$ of sodium salicylate solutions, enhancement of nimesulide solubility is very less significant. The dissolution of a solute (drug) in presence of a co-solute (i.e., hydrotropic agent) in ternary solutions may be explained in the light of (i) hydrophilic - ionic interactions between the hydrophilic sites $\left(\mathrm{H}-\mathrm{N}-\mathrm{SO}_{2} \mathrm{CH}_{3}\right)$ of nimesulide and the ions of the co-solute, and (ii) hydrophobic - ionic interactions between the hydrophobic parts of the nimesulide molecules and the ions of the co-solute. According to the co-sphere overlap model ${ }^{8}$, type (i) interactions favour the dissolution of nimesulide in all solutions of sodium benzoate, sodium salicylate 
(in higher molar concentrations), sodium bromide (in lower concentrations ) and nicotinamide, whereas the type (ii) interactions predominate over the former interactions in the lower concentrations of sodium salicylate $\left(0.1 \mathrm{~mol} \mathrm{dm}^{-3}\right.$ up to $\left.0.4 \mathrm{~mol} \mathrm{dm}^{-3}\right)$ and thereafter, slightly strengthening the hydrophilic-ionic interactions resulted in non significant increment in solubility with that concentration of the co-solute, sodium salicylate. The lowering of solubility of nimesulide in higher concentrations of sodium bromide might be due to the salting out effect of the drug in presence of the strong electrolyte sodium bromide in a dipolar solvent water. It may be stated here that the molecules of water join together to form clusters. For solubilisation, the ionised hydrotropes break this cluster and use the ion dipoles of water for deliverance. The increasing hydrotrope concentration results in unassociated form of water to make a cluster of hydrotrope by hydrogen bonding and non bonding interactions at various centers of drug (nimesulide) molecules. Thus charge delocalizing along with an increase in $\pi$ cloud area on hydrotropic molecule would account partially for difference in apparent solubility of nimesulide in the presence of various hydrotropic agents ${ }^{4}$.

\section{Densities}

The results of the density measurements are given in Table 1, along with the values of limiting apparent molar volume $\left(\Phi_{\mathrm{v}}{ }^{0}\right)$ and limiting apparent molar expansibility $\left(\Phi_{\mathrm{E}}{ }^{0}\right)$ of the hydrotropic agents in water and nimesulide in aqueous sodium benzoate, sodium salicylate, sodium bromide and nicotinamide solutions at 298.15, 303.15, 308.15, 313.15 K temperature. The values of $\Phi_{\mathrm{v}}{ }^{0}$ and $\Phi_{\mathrm{E}}{ }^{0}$ have been determined from the intercept of the plot of $\Phi_{\mathrm{v}} v s . \mathrm{c}^{1 / 2}$ and of $\Phi_{\mathrm{E}} v s . \mathrm{c}^{1 / 2}$, respectively, which ${ }^{9}$ are in turn determined form the experimentally measured densities as follows:

$$
\begin{gathered}
\Phi_{\mathrm{v}}=1000\left(\mathrm{~cd}_{0}\right)^{-1}\left(\mathrm{~d}_{0}-\mathrm{d}\right)+\mathrm{M}_{2} / \mathrm{d}_{0} \\
\quad \text { and } \\
\Phi_{\mathrm{E}}=\alpha \Phi_{\mathrm{v}}{ }^{0}+\left(\alpha-\alpha_{0}\right) 1000 \mathrm{c}^{-1}
\end{gathered}
$$

Where $\mathrm{c}$ is the molar concentration of the solute, $\mathrm{d}_{0}$ is the density of pure water, $\mathrm{d}$ is the density of the solution, $\mathrm{M}_{2}$ is the molecular mass of the solute and $\alpha_{0}$ and $\alpha$ are the coefficients of expansion of the solvent and solution (with or without drug), respectively, and determined by means of the relation available in the literature ${ }^{9}$. The $\Phi_{\mathrm{v}}$ and $\Phi_{\mathrm{E}}$ showed linear dependence with square root of concentration and were found to obey the linear equations,

$$
\begin{gathered}
\Phi_{\mathrm{v}}=\Phi_{\mathrm{v}}{ }^{0}+\mathrm{S}_{\mathrm{v}} \mathrm{c}^{1 / 2} \\
\quad \text { and } \\
\Phi_{\mathrm{E}}=\Phi_{\mathrm{E}}{ }^{0}+\mathrm{S}_{\mathrm{E}} \mathrm{c}^{1 / 2}
\end{gathered}
$$

The values of $S_{V}$ and $S_{E}$ obtained from the slopes of the corresponding plots are also given in Table 1. A perusal of Table 1, shows that the values of $\Phi_{\mathrm{v}}{ }^{0}$ are negative for the drug, nimesulide as well as for the hydrotropic agents at the experimental temperatures. Since the $\Phi_{\mathrm{v}}{ }^{0}$ is a measure of ion-solvent interaction, the negative values of $\Phi_{\mathrm{v}}{ }^{0}$ indicate weaker ion-solvent or drug-solvent interactions. The results indicate that the ion-solvent interactions decrease with increase in temperature, whereas the drug-solvent interactions in presence of hydrotropic agents increase with increase in temperature. The presence of ionsolvent or drug-solvent interaction between the molecules promotes the structure making effects of the drug in water + hydrotropic agent mixtures. 
Table 1. Density Parameters $\Phi_{\mathrm{v}}{ }^{0}\left(\mathrm{~cm}^{3} \mathrm{~mol}^{-1}\right), \mathrm{S}_{\mathrm{v}}\left(\mathrm{cm}^{9 / 2} \mathrm{~mol}^{-3 / 2}\right), \Phi_{\mathrm{E}}{ }^{0},\left(\mathrm{~cm}^{3} \mathrm{~mol}^{-1} \mathrm{~K}\right)$ and SE $\left(\mathrm{cm}^{9 / 2} \mathrm{~mol}^{-3 / 2} \mathrm{~K}^{-1}\right)$

\begin{tabular}{|c|c|c|c|c|c|}
\hline Sodium Benzoate & $\mathrm{T} / \mathrm{K}$ & $\Phi_{\mathrm{V}}{ }^{0}$ & $\mathrm{~S}_{\mathrm{V}}$ & $\Phi_{\mathrm{E}}^{0}$ & $\mathrm{~S}_{\mathrm{E}}$ \\
\hline Wod & 298.15 & -50.352 & 156.76 & 0.4296 & -6.7449 \\
\hline Wd & 298.15 & -40.998 & 146.54 & 0.1374 & -6.708 \\
\hline Wod & 303.15 & -45.565 & 154.18 & 0.1501 & -6.5974 \\
\hline $\mathrm{Wd}$ & 303.15 & -40.237 & 147.58 & 0.1326 & -6.5974 \\
\hline Wod & 308.15 & -42.418 & 151.71 & 0.138 & -6.4903 \\
\hline $\mathrm{Wd}$ & 308.15 & -41.263 & 149.82 & 0.1338 & -6.4904 \\
\hline Wod & 313.15 & -43.34 & 154.36 & 0.1377 & -6.3867 \\
\hline Wd & 313.15 & -40.196 & 149.62 & -1284 & -6.3863 \\
\hline Sodium Salicylate & $\mathrm{T} / \mathrm{K}$ & $\Phi_{\mathrm{V}}^{0}$ & $\mathrm{~S}_{\mathrm{V}}$ & $\Phi_{\mathrm{E}}^{0}$ & $\mathrm{~S}_{\mathrm{E}}$ \\
\hline Wod & 298.15 & -46.612 & 154.31 & 0.5314 & -60765 \\
\hline $\mathrm{Wd}$ & 298.15 & -42.693 & 149.42 & 0.1431 & -6.708 \\
\hline Wod & 303.15 & -51.691 & 162.05 & 0.1704 & -6.5975 \\
\hline Wd & 303.15 & -47.463 & 156.61 & 0.1565 & -6.5974 \\
\hline Wod & 308.15 & -53.922 & 166.06 & 0.1749 & -6.4901 \\
\hline Wd & 308.15 & -49.077 & 160.33 & 0.1592 & -6.4904 \\
\hline Wod & 313.15 & -32.54 & 161.46 & 0.1038 & -6.3871 \\
\hline Wd & 313.15 & -28.853 & 139.09 & -0.0922 & -6.3863 \\
\hline Sodium Bromide & $\mathrm{T} / \mathrm{K}$ & $\Phi_{\mathrm{V}}{ }^{0}$ & $\mathrm{~S}_{\mathrm{V}}$ & $\Phi_{\mathrm{E}}^{0}$ & $\mathrm{~S}_{\mathrm{E}}$ \\
\hline Wod & 298.15 & -35.515 & 78.899 & 0.5287 & -6.7572 \\
\hline Wd & 298.15 & -29.386 & 71.751 & 0.0985 & -6.708 \\
\hline Wod & 303.15 & -35.505 & 84.195 & 0.117 & -6.5975 \\
\hline Wd & 303.15 & -30.479 & 78.553 & 0.1004 & -6.5974 \\
\hline Wod & 308.15 & -24.99 & 79.117 & 0.081 & -6.4901 \\
\hline Wd & 308.15 & -31.82 & 82.54 & 0.1032 & -6.4904 \\
\hline Wod & 313.15 & -52.188 & 107.12 & 0.1666 & -6.3871 \\
\hline Wd & 313.15 & -32.736 & 85.5 & -1.1046 & -6.3863 \\
\hline Nicotinamide & $\mathrm{T} / \mathrm{K}$ & $\Phi_{\mathrm{V}}^{0}$ & $\mathrm{~S}_{\mathrm{V}}$ & $\Phi_{\mathrm{E}}^{0}$ & $\mathrm{~S}_{\mathrm{E}}$ \\
\hline Wod & 298.15 & -32.062 & 132.62 & 0.3018 & -6.7614 \\
\hline Wd & 298.15 & -22.432 & 121.42 & 0.0751 & -6.708 \\
\hline Wod & 303.15 & -30.746 & 133.29 & 0.1013 & -6.5975 \\
\hline Wd & 303.15 & -23.403 & 124.37 & 0.0771 & -6.5974 \\
\hline Wod & 308.15 & -22.12 & 124.39 & 0.0717 & -6.4901 \\
\hline $\mathrm{Wd}$ & 308.15 & -20.982 & 122.97 & 0.068 & -6.4904 \\
\hline Wod & 313.15 & -25.826 & 129.23 & 0.0824 & -6.3871 \\
\hline $\mathrm{Wd}$ & 313.15 & -17.025 & 119.03 & -0.0544 & -6.3863 \\
\hline
\end{tabular}

Wod; Without drug, Wd; With drug

As observed, the $S_{V}$ values are positive and high at the experimental temperatures for the systems with or without drug. This suggests the presence of ion -ion or solute-solute interaction in the system. Further, it is seen that the values of $S_{V}$ for the system in the presence of drug are less as compared to those in the absence of drug. This point to the fact that the solvent structure is not too much enhanced in the presence of drug.

The standard partial molar volume of transfer, $\Delta_{\mathrm{t}} \Phi_{\mathrm{v}}{ }^{0}$ at infinite dilution of nimesulide (drug) from water to aqueous (sodium benzoate, sodium salicylate, sodium bromide and nicotinamide) solutions have been determined as follows: 


$$
\Delta_{\mathrm{t}} \Phi_{\mathrm{v}}{ }^{0}=\Phi_{\mathrm{v}}{ }^{0} \text { (in aqueous hydrotropic solutions) }-\Phi_{\mathrm{v}}{ }^{0} \text { (in water) }
$$

It is seen that the values of $\Delta_{\mathrm{t}} \Phi_{\mathrm{v}}{ }^{0}$ are positive for all the systems at the experimental temperatures and decrease with increase in temperature. Dehydration of ions (cation and anion of the hydrotropic agent) and drug (nimesulide) molecules may also make positive contributions to the $\Delta_{\mathrm{t}} \Phi_{\mathrm{v}}{ }^{0}$ values. This may be due to the destructive overlap of cospheres resulting in the net decrease in solvation thereby increasing the solute (drug) volume and because of the strong interactions between the drug and the hydrotropic agent; the latter lose their effect on the water structure.

The values of $\Phi_{\mathrm{E}}{ }^{0}$ for all the systems at all temperatures (except at $313.15 \mathrm{~K}$ for all the systems with the drug) are small but positive and vary irregularly with increase of temperature. However, the values of $\Phi_{\mathrm{E}}{ }^{0}$ in the presence of drug indicated the absence of caging or packing effect ${ }^{10}$ supporting to the earlier contention that the solvent structure is not too much enhanced.

\section{Viscosities}

The measured viscosity values of aqueous solutions of sodium benzoate, sodium salicylate, sodium bromide and nicotinamide with and without nimesulide in the temperature range between 298.15 and $313.15 \mathrm{~K}$ revealed that the measured viscosities increase with increasing hydrotropic agents concentration with and without nimesulide and the measured viscosity values of the solutions containing nimesulide are found to be more than the values without nimesulide. The temperature influences strongly the viscosity in the fact that the viscosity values decrease with increase of temperature.

The viscosity data of the aqueous solutions of sodium benzoate, sodium salicylate, sodium bromide and nicotinamide with and without nimesulide have been analyzed by the Jones-Dole equation ${ }^{11}$

$$
\eta / \eta_{0}=1+A_{F} c^{1 / 2}+B_{J} c
$$

Where $\eta$ and $\eta_{0}$ are the viscosities of the solution and the solvent, respectively, $A_{F}$ is the constant characteristic of the solute and $\mathrm{B}_{\mathrm{J}}$ is the jones-dole coefficient and were obtained from the intercept and slope of the plot of $\left(\eta / \eta_{0}-1\right) / c^{1 / 2} v s . c^{1 / 2}$ and are recorded in Table 2.

As observed, the values of $\mathrm{A}_{\mathrm{F}}$ are positive (excluding a few cases; in sodium benzoate solutions at $298.15,303.15$ and $308.15 \mathrm{~K}$, in sodium bromide solutions at $303.15 \mathrm{~K}$ and in nicotinamide solutions at 303.15 and $308.15 \mathrm{~K}$ without drug) and vary irregularly with increase of temperature. Since $A_{F}$ is a measure of ion -ion or solute-solute interaction, the positive $A_{F}$ values indicate solute-solute interaction in conformity with the positive values of $\mathrm{S}_{\mathrm{V}}($ c.f. Table 1)

On the other hand, the negative values of $\mathrm{A}_{\mathrm{F}}$ in some sodium benzoate solutions support to the higher solubility of nimesulide in these solutions. The co-efficient $\mathrm{B}_{\mathrm{J}}$ is a measure of effective hydrodynamic volume of the solvated ion/solute and is governed by the ion/solutesolvent interactions, that is, the structure of the solvent in the solution. It is a fact that when a solute dissolves in a solvent, some of the solvent molecules are attached to the ion / solute molecules because of the ion/solute -solvent interactions and this causes an increase in the viscosity of the solution. This is consistent with the measured viscosity values of the solutions with and without added drug. On the other hand, the solvent molecules are to be wrenched out of the bulk of the solvent and this breaking of the solvent structure causes a decrease in the viscosity of the solution. In other words, formation of the transition state is accompanied by rupture and distortion of intermolecular forces in solvent structure. That is why, the viscosity values of the solutions with and without the drug decrease with increase in temperature. 
Table 2. Values of the parameters $A_{F}\left(\mathrm{dm}^{3 / 2} \mathrm{~mol}^{-1 / 2}\right), \mathrm{B}_{\mathrm{J}}\left(\mathrm{dm}^{3} \mathrm{~mol}^{-1}\right), \Delta \mu_{1}{ }^{0 *}\left(\mathrm{~kJ} \mathrm{~mol}^{-1}\right)$ and $\Delta \mu_{2}{ }^{0 *}\left(\mathrm{~kJ} \mathrm{~mol}^{-1}\right)$

\begin{tabular}{|c|c|c|c|c|c|}
\hline Sodium Benzoate & $\mathrm{T} / \mathrm{K}$ & $A_{F}$ & $\mathrm{~B}_{\mathrm{J}}$ & $\Delta \mu_{1}{ }^{0^{*}}$ & $\Delta \mu_{2}{ }^{*}$ \\
\hline Wod & 298.15 & -0.1275 & 0.7058 & 9.15 & 157.56 \\
\hline $\mathrm{Wd}$ & 298.15 & -0.135 & 0.7209 & 9.15 & 159.64 \\
\hline Wod & 303.15 & -0.0617 & 0.5538 & 9.05 & 138.67 \\
\hline $\mathrm{Wd}$ & 303.15 & -0.0491 & 0.5504 & 9.05 & 140.78 \\
\hline Wod & 308.15 & -0.0916 & 0.5544 & 8.94 & 140.78 \\
\hline $\mathrm{Wd}$ & 308.15 & -0.0767 & 0.5448 & 8.94 & 139.42 \\
\hline Wod & 313.15 & 0.0775 & 0.3903 & 8.84 & 119.4 \\
\hline $\mathrm{Wd}$ & 313.15 & 0.0674 & 0.4056 & 8.84 & 121.32 \\
\hline Sodium Salicylate & $\mathrm{T} / \mathrm{K}$ & $\mathrm{A}_{\mathrm{F}}$ & $\mathrm{B}_{\mathrm{J}}$ & $\Delta \mu_{1}{ }^{0}$ & $\Delta \mu_{2}{ }^{0}$ \\
\hline Wod & 298.15 & 0.1722 & 0.5437 & 9.15 & 135.26 \\
\hline Wd & 298.15 & 0.185 & 0.5342 & 9.15 & 133.96 \\
\hline Wod & 303.15 & 0.0546 & 0.4596 & 9.05 & 125.48 \\
\hline $\mathrm{Wd}$ & 303.15 & 0.0858 & 0.4389 & 9.05 & 122.59 \\
\hline Wod & 308.15 & 0.0205 & 0.4662 & 8.94 & 128.23 \\
\hline Wd & 308.15 & 0.0595 & 0.4326 & 8.94 & 123.46 \\
\hline Wod & 313.15 & 0.1311 & 0.3242 & 8.84 & 109.56 \\
\hline $\mathrm{Wd}$ & 313.15 & 0.1839 & 0.3109 & 8.84 & 107.64 \\
\hline Sodium Bromide & $\mathrm{T} / \mathrm{K}$ & $\mathrm{A}_{\mathrm{F}}$ & $\mathrm{B}_{\mathrm{J}}$ & $\Delta \mu_{1}{ }^{0}$ & $\Delta \mu_{2}{ }^{0}$ \\
\hline Wod & 298.15 & 0.2697 & -0.0385 & 9.15 & 551.77 \\
\hline $\mathrm{Wd}$ & 298.15 & 0.2853 & -0.0481 & 9.15 & 538.62 \\
\hline Wod & 303.15 & -0.0332 & 0.1571 & 9.05 & 831.87 \\
\hline Wd & 303.15 & -0.0126 & 0.1497 & 9.05 & 821.57 \\
\hline Wod & 308.15 & 0.0215 & 0.1279 & 8.94 & 801.55 \\
\hline $\mathrm{Wd}$ & 308.15 & 0.0181 & 0.1375 & 8.94 & 815.14 \\
\hline Wod & 313.15 & 0.0444 & 0.115 & 8.84 & 793.14 \\
\hline Wd & 313.15 & 0.057 & 0.1094 & 8.84 & 785.24 \\
\hline Nicotinamide & $\mathrm{T} / \mathrm{K}$ & $\mathrm{A}_{\mathrm{F}}$ & $\mathrm{B}_{\mathrm{J}}$ & $\Delta \mu_{1}{ }^{0}$ & $\Delta \mu_{2}^{0}$ \\
\hline Wod & 298.15 & 0.2258 & 0.126 & 9.15 & 778.11 \\
\hline Wd & 298.15 & 0.2254 & 0.1327 & 9.15 & 787.43 \\
\hline Wod & 303.15 & -0.0096 & 0.2711 & 9.05 & 991.38 \\
\hline $\mathrm{Wd}$ & 303.15 & 0.0032 & 0.2713 & 9.05 & 991.74 \\
\hline Wod & 308.15 & -0.0037 & 0.2593 & 8.94 & 988.41 \\
\hline Wd & 308.15 & 0.0002 & 0.2586 & 8.94 & 987.43 \\
\hline Wod & 313.15 & 0.0919 & 2074 & 8.84 & 926.91 \\
\hline $\mathrm{Wd}$ & 313.15 & 0.0947 & 0.2115 & 8.84 & 932.93 \\
\hline
\end{tabular}

The values of the coefficient $B_{J}$ for all the systems, except sodium bromide solutions with and without nimesulide at $298.15 \mathrm{~K}$ only are positive and thus indicating the presence of ion/solute-solvent interaction. It is found that the values of $B_{J}$ vary irregularly with increase in temperature for all the systems and this point to the fact that the coefficient $\mathrm{B}_{\mathrm{J}}$ is highly specific property of the individual solute and is strongly temperature dependent. As the value of $\mathrm{dB}_{\mathrm{J}} / \mathrm{dt}$ is a better criterion for determining solute- solvent interaction, the $\mathrm{dB}_{\mathrm{J}} / \mathrm{dt}>0$ in all the solutions shows that the solute (both the hydrotropic agents and the drug, nimesulide) behave as net structure makers in aqueous solutions. The viscosity data were also analyzed on the basis of transition theory for relative viscosity suggested by Feakins ${ }^{12}$.

$$
\Delta \mu_{2}{ }^{0 *}=\Delta \mu_{1}{ }^{0 *}+\left(\mathrm{RT} / \mathrm{V}_{1}{ }^{0}\right) 1000 \mathrm{~B}_{\mathrm{J}}-\left(\mathrm{V}_{1}{ }^{0}-\mathrm{V}_{2}{ }^{0}\right)
$$


Where $\Delta \mu_{2}{ }^{0 *}$ is the contribution per mole of the solute to free energy of activation for viscous flow of the solution, $\Delta \mu_{1}{ }^{*}$ is the corresponding value for pure solvent, $\mathrm{V}_{1}{ }^{0}$ is the partial molar volume of the solvent, $\mathrm{V}_{2}{ }^{0}$ is the partial molar volume of the solute, $\mathrm{B}_{\mathrm{J}}$ is the Jones-Dole parameter. $\Delta \mu_{1}{ }^{0 *}$ was calculated from the following equation.

$$
\Delta \mu_{1}{ }^{0 *}=\mathrm{RT} \ln \left(\eta_{0} \mathrm{~V}_{1}{ }^{0} / \mathrm{hN}\right)
$$

Where $\mathrm{h}$ is the Planck's constant, $\mathrm{N}$ is the Avogadro number and $\eta_{0}$ is viscosity of the pure solvent. The values of $\Delta \mu_{1}{ }^{0 *}$ and $\Delta \mu_{2}{ }^{0 *}$ are also given in Table 2 . The positive and larger values of $\Delta \mu_{2}{ }^{0 *}$ (as compared to that of $\Delta \mu_{1}{ }^{0 *}$ ) indicate the presence of strong solute- solvent interactions. In other words, as pointed out above, the formation of the transition state is accompanied by the rupture and distortion of intermolecular forces in solvent structure.

\section{Conclusion}

In this study, solubilities, densities and viscosities for the (hydrotropic agents + water with or without nimesulide) systems were determined at the temperature range between 298.15 and $313.15 \mathrm{~K}$. The principal conclusions that we reached are as follows:

1. The solubility of nimesulide in aqueous solutions of hydrotropic agents follows the order: sodium benzoate $>$ nicotinamide $>$ sodium salicylate $>$ sodium bromide, which is the order of the basic nature of the aqueous solutions of these hydrotropic agents. These results suggest that at the lower hydrotropic concentration, weak ionic interaction and at higher hydrotropic concentration, the formation of molecular aggregates is the possible mechanisms of the hydrotropic solubilisation.

2. The standard partial molar volume $\left(\Phi_{\mathrm{v}}{ }^{0}\right)$ for the systems are negative indicating the weak ion/solute -solvent or drug-solvent interaction. Further, the standard partial molar volumes of transfer $\Delta_{\mathrm{t}} \Phi_{\mathrm{v}}{ }^{0}$ are positive and decrease with increase of temperature. This suggests that these studied hydrotropes have the dehydration effect on the drug, nimesulide.

3. The viscosity values of the solutions with and without the drug decrease with increase of temperature pointing to the fact that formation of the transition state is accompanied by the rupture and the distortion of intermolecular forces in solvent structure and the solutes behave as the net structure makers in aqueous solutions.

\section{References}

1. American hospital formulary services, American society of health system pharmacists, 1998, 1617.

2. Drug information for health care professional, $17^{\text {th }}$ Ed., USPDI, 1997, 1646.

3. Agrawal S, Pancholi S S, Jain N K and Agrawal G P, Int J Pharm., 2004, 274, 149-155.

4. Poochkian G D and Gradock J C, J Pharm Sci., 1974, 68, 728-732.

5. Robinson R A and Stokes R H, Electrolyte Solutions, Butterworth publications, London, 1955, 30.

6. Kell G S, J Chem Eng Data, 1967, 20, 97-105.

7. Watson J T R, Basu R S and Sengers J V, J Phys Chem Ref Data, 1980, 9, 1255-1290.

8. Gurney R W, Ionic Processes in Solutions, McGraw Hill, New York, 1953.

9. Harned H S and Owen B B, The Physical Chemistry of Electrolyte Solutions, Third Ed., Reinhold, NewYork, 1958, 358.

10. Millero F J, Structure and Transport Processes in Water and Aqueous Solutions, Edited by R.A. Horne, Wiely Interscience, New York, Ch. 1971,15.

11. Dash U N, Patnaik M R and Bhattacharjee C R, J Mol Liquids, 1998, 75, 253-260.

12. Taniewska-Osinska S and Jozwiak M, J Chem Farady Trans, 1989, 85, 2141-2147. 


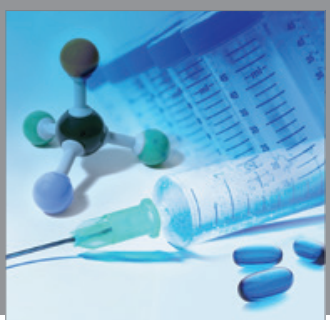

International Journal of

Medicinal Chemistry

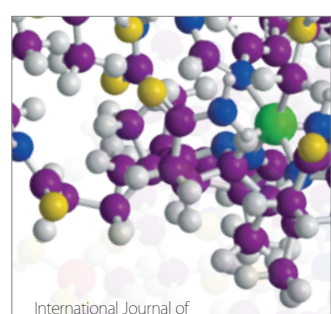

Carbohydrate Chemistry

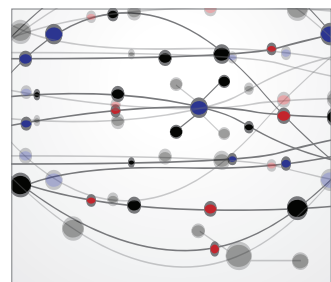

The Scientific World Journal
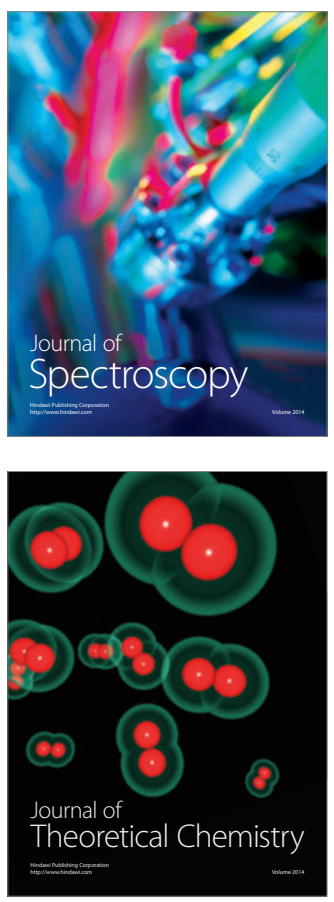
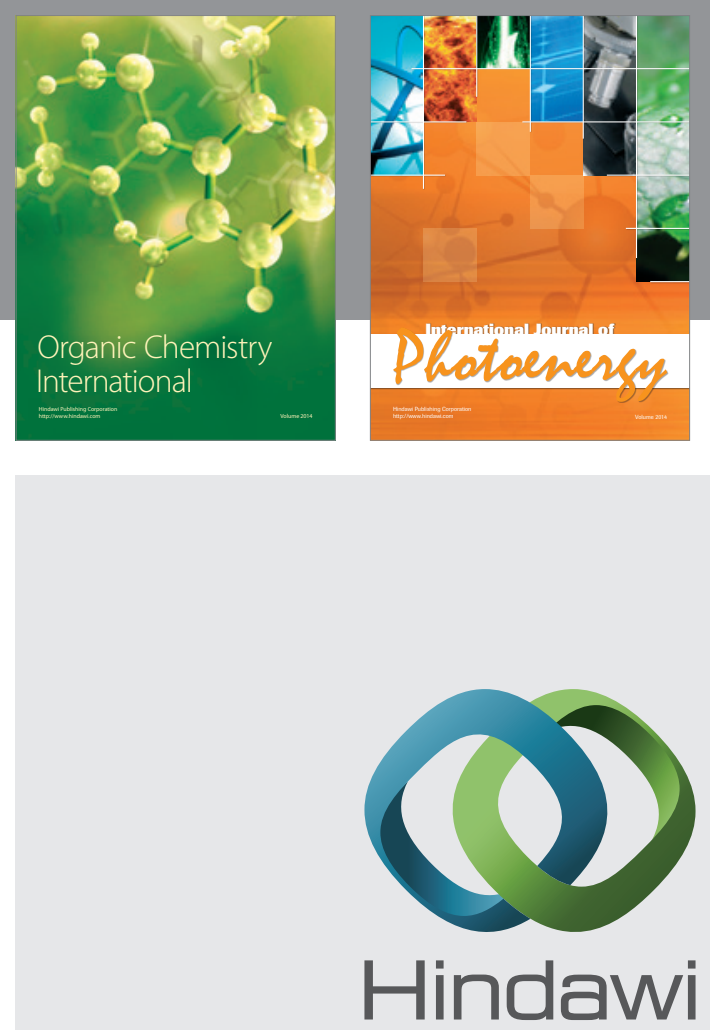

Submit your manuscripts at

http://www.hindawi.com
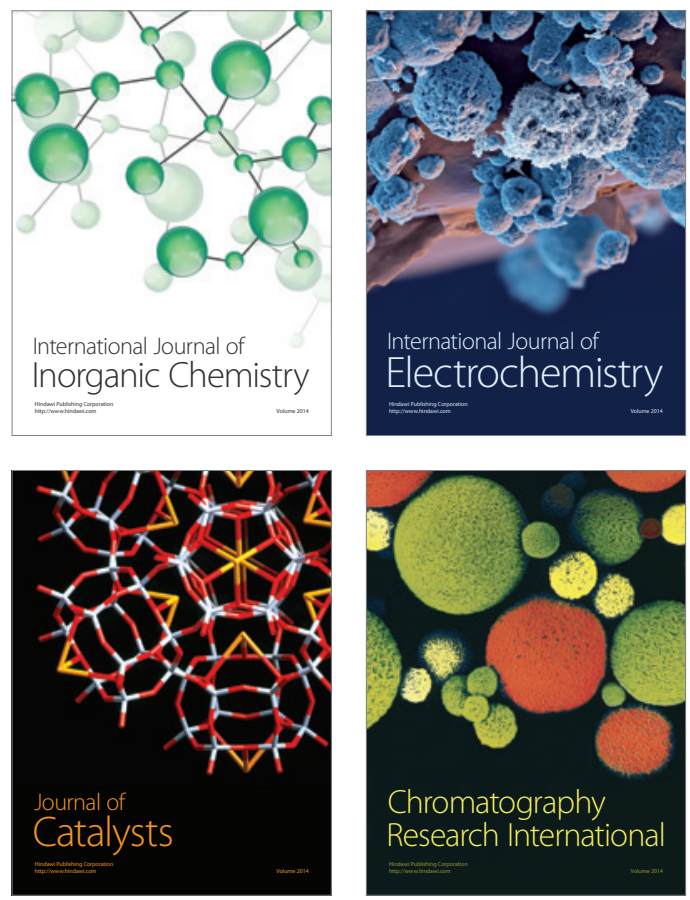
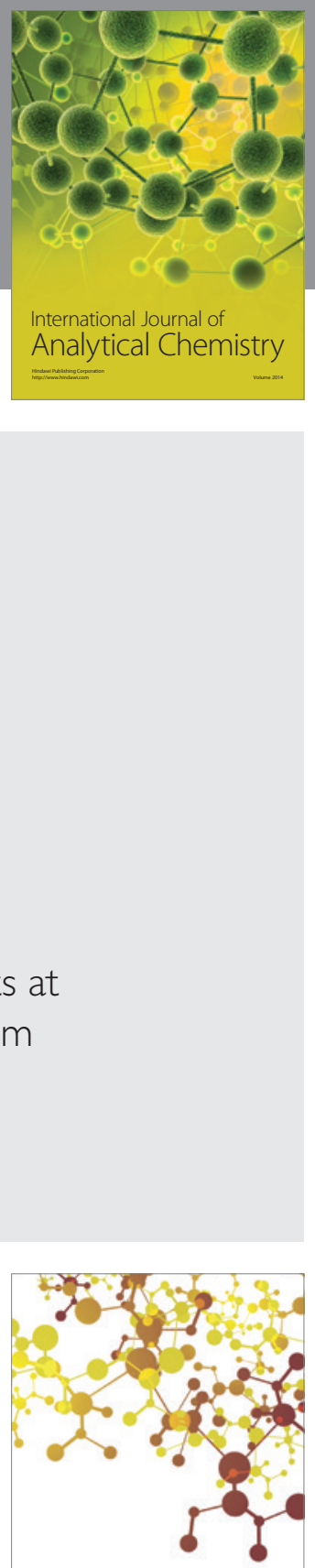

Journal of

Applied Chemistry
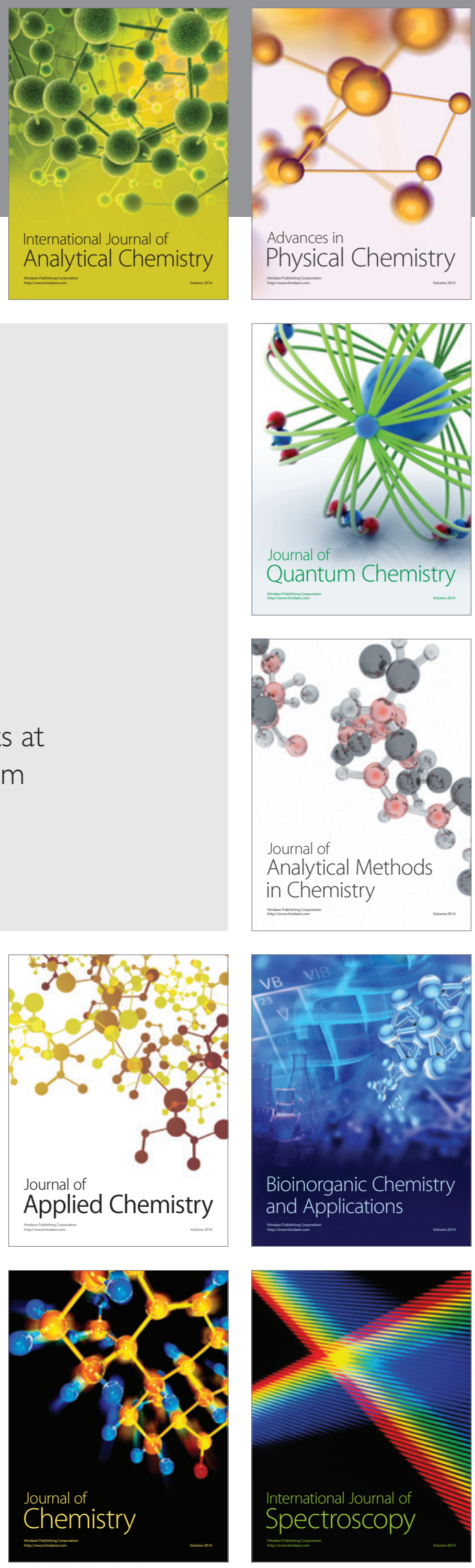